\title{
Increasing Malaria Parasite Clearance Time after Chloroquine Therapy, South Korea, 2000-2016
}

Seong Yeon Park, Yoon Soo Park, Yoonseon Park, Yee Gyung Kwak, Je Eun Song, Kkot Sil Lee, Shin-Hyeong Cho, Sang-Eun Lee, Hyun-II Shin, Joon-Sup Yeom

We reviewed the clinical efficacy of chloroquine for Plasmodium vivax malaria, the changing trend of parasite clearance time, and fever clearance time during 20002016 in South Korea. Median parasite clearance time and fever clearance time increased significantly over the study period. Chloroquine was mostly underdosed when used to treat $P$. vivax malaria.

Plash lasmodium vivax is the only form of malaria indigenous to South Korea (1); combination chloroquine and primaquine therapy has been the mainstay of vivax malaria treatment. After $P$. vivax reemerged after being eliminated in South Korea in the late 1970s, it mainly occurred in soldiers or veterans stationed in the demilitarized zone between North Korea and South Korea. Because of this focus, mass chloroquine chemoprophylaxis has been administered in place for soldiers working in high-risk areas since 1997 (2,3). However, there is concern that mass chemoprophylaxis might lead to reduced chloroquine susceptibility (2). In addition, soldiers were often given lower doses than that recommended by the World Health Organization (WHO); Commons et al. reported that underdosing of chloroquine was associated with recurrence and increased parasite clearance time (PCT) (4). We studied the trends in South Korea during 2000-2016 for treatment efficacy on the basis of PCT and fever clearance time (FCT).

Author affiliations: Dongguk University Ilsan Hospital,

Gyeonggi-do, South Korea (S.Y. Park); National Health Insurance Service Ilsan Hospital, Gyeonggi-do (Y.S. Park, Y. Park); Inje

University Ilsan Paik Hospital, Gyeonggi-do (Y.G. Kwak,

J.E. Song); Myongji Hospital, Gyeonggi-do (K.S. Lee);

Korea Centers for Disease Control and Prevention,

Chungcheongbuk-do, South Korea (S.-H. Cho, S.-E. Lee,

H.-I. Shin); Yonsei University College of Medicine, Seodaemun-gu,

Seoul, South Korea (J.-S. Yeom)

DOI: https://doi.org/10.3201/eid2608.190687

\section{The Study}

We conducted this study in 4 hospitals in Goyang, Gyeonggi Province, and 1 hospital in Seoul. The study population consisted of patients $>18$ years of age in whom $P$. vivax malaria had been diagnosed during 2000-2016 and who had been prescribed chloroquine alone or in combination with primaquine. We determined PCT, defined as the time in hours from chloroquine administration until the first blood smear negative for parasites after which the patient's follow-up smears were also negative, from malaria smears taken daily in routine treatment of patients. To determine FCT, defined as the time from chloroquine administration until the patient's body temperature decreased to $<37.5^{\circ} \mathrm{C}$ for 48 consecutive hours (5), we checked for fever every 4-6 hours or whenever the patient felt febrile.

This study was approved by the local institutional review board. Statistical analyses were performed with SPSS Statistics 20 (IBM, https:/ / www.ibm.com). For PCT and FCT, we reported median and interquartile ranges (IQR) because Shapiro-Wilk test results showed that outcome measures did not follow a normal distribution. We compared trend analyses for PCT and FCT by enrollment periods using a linearby-linear association.

We analyzed included data from a total of 1,199 malaria cases over the 17-year study period. The mean $( \pm \mathrm{SD})$ age of patients was $41.7 \pm 14.2$ years. None of the patients died of malaria during the study period; 44 relapsed. We divided the years of the study period into 3 ranges. During 2000-2005, 404 malaria cases occurred; that number increased to 566 during 2006-2010, then decreased to 229 during 2011-2016. (Table 1).

Median PCT increased from 63.0 hours during 2000-2005 to 75.0 hours during 2011-2016 $(\mathrm{p}<0.001)$. The proportion of patients whose PCT 
Parasite Clearance Time after Chloroquine Therapy

was $>48$ hours significantly increased over the 17 years from $76.3 \%$ during $2000-2005$ to $86.6 \%$ during 2011-2016 ( $p=0.03)$. In addition, the proportion of PCT at $>72$ hours also significantly increased from $30.5 \%$ during $2000-2005$ to $52.4 \%$ during $2011-2016$ $(\mathrm{p}=0.005)$.

We found fever in 1,074 (89.6\%) of 1,199 patients at the time $P$. vivax malaria was diagnosed. Among those patients, median FCT increased from 28.0 hours during 2000-2005 to 48.0 hours during 2011-2016 $(p<0.001)$. The proportion of patients whose FCT was $>48$ hours increased from $17.6 \%$ during $2000-2005$ to $48.1 \%$ during $2011-2016(\mathrm{p}<0.001)$. The proportion of patients whose FCT was $>72$ hours also increased significantly from $5.7 \%$ during $2000-2005$ to $16.0 \%$ during 2011-2016 ( $\mathrm{p}=0.001)$.

All of the study patients were treated with either hydroxychloroquine or chloroquine phosphate. The mean total dose of chloroquine base administered was $23.0 \mathrm{mg} / \mathrm{kg}$ body weight in 838 patients (69.9\%), which is less than the WHO-recommended target dose of $25 \mathrm{mg} / \mathrm{kg}$. The trend of the mean of the total dose of chloroquine base decreased from $23.5 \mathrm{mg} / \mathrm{kg}$ during 2000-2005 to $22.1 \mathrm{mg} / \mathrm{kg}$ during 2011-2016 $(p<0.001)$. In addition, the proportion of patients receiving less than the WHO-recommended dose increased from $68.8 \%$ during $2000-2005$ to $77.3 \%$ during 2011-2016 ( $\mathrm{p}=0.02)$.

Comparing patients with mean total chloroquine doses of $\geq 25 \mathrm{mg} / \mathrm{kg}$ or $<25 \mathrm{mg} / \mathrm{kg}$, we found that men were more likely than women to be in the $<25 \mathrm{mg} / \mathrm{kg}$ group $(84.2 \%$ vs. $44.9 \% ; \mathrm{p}<0.001)$ (Table 2). Median FCT was longer in the $<25 \mathrm{mg} / \mathrm{kg}$ group (65.0 h vs. $62.5 \mathrm{~h} ; \mathrm{p}=0.02$ ) and patients whose fever lasted $>72$ hours were more common in the $<25 \mathrm{mg} /$ $\mathrm{kg}$ group $(12.1 \%$ vs. $7.8 \%$; $\mathrm{p}=0.03)$. Relapse was also more common in this group $(4.7 \%$ vs. $1.4 \%$; $=0.003)$.

\section{Conclusions}

In this study, we made 2 important findings. First, the trend of increased PCT and FCT in South Korea might be ascribed to decreased $P$. vivax susceptibility to chloroquine that could be seen before the emergence of WHO-recognized drug resistance. Mass chemoprophylaxis of military personnel with hydroxychloroquine started in 1997 in South Korea $(3,6)$. However, mass chemoprophylaxis with poor compliance to recommended dosing among the patients increased the possibility of chloroquine-resistant strains of $P$. vivax emerging. This finding may explain the failure of the prophylactic hydroxychloroquine treatment to widely protect South Korean army soldiers from $P$. vivax malaria by 2000 , chloroquine-resistant cases occurring by the early to mid-2000s (7), and the increase in PCT after chloroquine treatment since the late 2000s (2).

Second, in areas with chloroquine-sensitive $P$. vivax, WHO recommends oral chloroquine at a total dose of $25 \mathrm{mg}$ base $/ \mathrm{kg}$. Lower total doses are not recommended because they encourage the emergence of resistance (8). However, in the current study, $\approx 70 \%$ of patients received a suboptimal dose $(<25$ $\mathrm{mg} / \mathrm{kg}$ ) of chloroquine, partly because the total dose of chloroquine administered in South Korea was usually fixed at $1,500 \mathrm{mg}$ base, as recommended by the US Centers for Disease Control and Prevention (9), rather than a weight-based dose. In our study, the average body weight of patients significantly

\begin{tabular}{|c|c|c|c|c|}
\hline \multirow[b]{2}{*}{ Variable } & \multicolumn{3}{|c|}{ Years } & \multirow[b]{2}{*}{$p$ value } \\
\hline & $2000-2005, n=404$ & $2006-2010, n=566$ & $2011-2016, n=229$ & \\
\hline Age, y, mean $( \pm S D)$ & $40.5 \pm 14.3$ & $42.5 \pm 14.0$ & $41.6 \pm 14.6$ & 0.06 \\
\hline \multicolumn{5}{|l|}{ Sex } \\
\hline$M$ & $279(69.1)$ & $410(72.4)$ & 179 (78.2) & 0.045 \\
\hline $\mathrm{F}$ & $125(30.9)$ & $156(27.6)$ & $50(21.8)$ & \\
\hline Weight, kg, mean ( $\pm S D)$ & $66.3 \pm 0.57$ & $68.4 \pm 0.53$ & $70.5 \pm 0.88$ & $<0.001$ \\
\hline Smear follow-up & $131(32.4)$ & $168(29.7)$ & $82(35.8)$ & 0.23 \\
\hline Median PCT (IQR), h & $63.0(49.0-82.0)$ & $66.0(56.3-78.0)$ & $75.0(52.0-96.5)$ & $<0.001$ \\
\hline PCT $>48 \mathrm{~h}$ & $100 / 131(76.3)$ & $145 / 168(86.3)$ & $71 / 82(86.6)$ & 0.03 \\
\hline $\mathrm{PCT}>72 \mathrm{~h}$ & $40 / 131(30.5)$ & $61 / 168(36.3)$ & $43 / 82(52.4)$ & 0.005 \\
\hline Fever & $347(85.9)$ & $521(92.0)$ & $206(90.0)$ & 0.04 \\
\hline Median FCT (IQR), h & $28.0(14.0-42.0)$ & $43.0(29.0-59.0)$ & $48.0(28.0-66.0)$ & $<0.001$ \\
\hline FCT $>48 \mathrm{~h}$ & $49 / 279(17.6)$ & $198 / 477(41.5)$ & $87 / 181(48.1)$ & $<0.001$ \\
\hline FCT $>72 \mathrm{~h}$ & $16 / 279(5.7)$ & $54 / 477(11.3)$ & $29 / 181(16.0)$ & 0.001 \\
\hline $\mathrm{CQ}, \mathrm{mg} / \mathrm{kg}$, mean $( \pm \mathrm{SD})$ & $23.5 \pm 5.0$ & $22.9 \pm 4.4$ & $22.1 \pm 4.8$ & 0.001 \\
\hline $\mathrm{CQ}<25 \mathrm{mg} / \mathrm{kg}$ & $278(68.8)$ & $383(67.7)$ & $177(77.3)$ & 0.02 \\
\hline Primaquine, $\mathrm{mg} / \mathrm{kg}$, mean $( \pm \mathrm{SD})$ & $0.23 \pm 0.06$ & $0.24 \pm 0.06$ & $0.29 \pm 0.12$ & $<0.001$ \\
\hline Primaquine $<0.25$ & $265 / 373(71.0)$ & $343 / 543(63.2)$ & $114 / 221(51.6)$ & $<0.001$ \\
\hline Relapse & 9/394 (2.3) & $20 / 541(3.7)$ & $10 / 220(4.5)$ & 0.20 \\
\hline
\end{tabular}


Table 2. Comparison of clinical features for patients with Plasmodium vivax malaria, according to the dosage of chloroquine, South Korea*

\begin{tabular}{|c|c|c|c|}
\hline Variable & $\mathrm{CQ} \geq 25 \mathrm{mg} / \mathrm{kg}, \mathrm{n}=361$ & $\mathrm{CQ}<25 \mathrm{mg} / \mathrm{kg}, \mathrm{n}=838$ & $p$ value \\
\hline Age, $y$, mean $( \pm S D)$ & $42.6 \pm 16.2$ & $41.2 \pm 13.2$ & 0.13 \\
\hline \multicolumn{4}{|l|}{ Sex } \\
\hline M & $162(44.9)$ & $706(84.2)$ & $<0.001$ \\
\hline $\mathrm{F}$ & $199(55.1)$ & $132(15.8)$ & \\
\hline Positive for underlying disease & $66(18.3)$ & $144(17.2)$ & 0.35 \\
\hline Primaquine administration & $350(97.0)$ & $831(99.2)$ & 0.006 \\
\hline Primaquine, $\mathrm{mg} / \mathrm{kg}$, mean $( \pm S D)$ & $0.27(0.25-0.30)$ & $0.21(0.19-0.23)$ & $<0.001$ \\
\hline Smear follow-up & $122(33.8)$ & $259(30.9)$ & 0.18 \\
\hline Median PCT (IQR), h & $62.5(51.8-81.8)$ & $65.0(52.0-81.0)$ & 0.19 \\
\hline $\mathrm{PCT}>48 \mathrm{~h}$ & 98/122 (80.3) & $215 / 259(83.0)$ & 0.31 \\
\hline $\mathrm{PCT}>72 \mathrm{~h}$ & $37 / 122(30.3)$ & $91 / 259(35.1)$ & 0.21 \\
\hline Fever & 322 (89.2) & $752(89.7)$ & 0.43 \\
\hline Median FCT (IQR), h & $37.0(23.0-54.0)$ & $38.0(24.0-48.0)$ & 0.02 \\
\hline $\mathrm{FCT}>48 \mathrm{~h}$ & 98/295 (33.2) & $238 / 647(36.8)$ & 0.16 \\
\hline $\mathrm{FCT}>72 \mathrm{~h}$ & $23 / 295(7.8)$ & $78 / 647(12.1)$ & 0.03 \\
\hline Relapse & $5(1.4)$ & $39(4.7)$ & 0.003 \\
\hline
\end{tabular}

increased, from $66 \mathrm{~kg}$ during 2000-2005 to $71 \mathrm{~kg}$ during 2011-2016 ( $\mathrm{p}<0.001)$, but the recommended total fixed dose of chloroquine did not change. On the basis of the WHO recommendation of $25 \mathrm{mg} / \mathrm{kg}$ base, a total dose of chloroquine of 1,500 $\mathrm{mg}$ base would have been inadequate for patients whose body weight was $>60 \mathrm{~kg}$. In our study, we also found that relapse was more common in the $<25 \mathrm{mg} / \mathrm{kg}$ chloroquine dose group $(4.7 \%$ vs $1.4 \%$; $p=0.003)$.

This study has several limitations. First, parasite clearance was identified in only one third of study patients, but malaria smears were taken once daily, so clearance of parasites could have occurred at any hour in the interval between slides being taken, which could have affected the calculation of PCT. Second, temperature measurements might have been affected by the use of antipyretics and patients were not checked for fever hourly during hospitalization, either of which could have affected the calculation of FCT. Third, due to the retrospective nature of the study, we could not obtain other information that might affect estimates of PCT, such as patient vomiting, which indicates that the medication may not have been absorbed normally, or FCT, such as duration of fever before malaria diagnosis. Prospective studies are needed to more accurately assess whether PCT or FCT has increased.

In summary, increased PCT and FCT might be ascribed to reduced parasite susceptibility to chloroquine that could be seen before emergence of drug resistance in South Korea. Therefore, a proactive and continuous surveillance system for PCT and FCT is needed. In addition, chloroquine is mostly underdosed in the treatment of $P$. vivax malaria in South Korea; thus, clinicians should adhere to weight-based treatment guidelines.
This study was supported by a grant from the Korea Centers for Disease Control and Prevention (grant no. 2016-E54004-00), South Korea.

\section{About the Author}

Dr. Seong Yeon Park is a professor in the department of infectious diseases, Dongguk University, South Korea. Her research interests include malaria and other viral diseases.

\section{References}

1. Feighner BH, Pak SI, Novakoski WL, Kelsey LL, Strickman D. Reemergence of Plasmodium vivax malaria in the republic of Korea. Emerg Infect Dis. 1998;4:295-7. https:/ /dx.doi.org/10.3201/eid0402.980219

2. Yeom JS, Jun G, Kim JY, Lee WJ, Shin EH, Chang KS, et al. Status of Plasmodium vivax malaria in the Republic of Korea, 2008-2009: decrease followed by resurgence. Trans R Soc Trop Med Hyg. 2012;106:429-36. https:/ / doi.org/ 10.1016/j.trstmh.2012.03.011

3. Im JH, Huh K, Yoon CG, Woo H, Lee JS, Chung MH, et al. Malaria control and chemoprophylaxis policy in the Republic of Korea Armed Forces for the previous 20 years (1997-2016). Malar J. 2018;17:295. https:// doi.org/10.1186/ s12936-018-2449-4

4. Commons RJ, Simpson JA, Thriemer K, Humphreys GS, Abreha T, Alemu SG, et al. The effect of chloroquine dose and primaquine on Plasmodium vivax recurrence: a WorldWide Antimalarial Resistance Network systematic review and individual patient pooled meta-analysis. Lancet Infect Dis. 2018;18:1025-34. https:/ / doi.org/10.1016/ S1473-3099(18)30348-7s

5. Subramony H, Tangpukdee N, Krudsood S, Poovorawan K, Muangnoicharoen S, Wilairatana P. Evaluation of efficacy of chloroquine for Plasmodium vivax infection using parasite clearance times: a 10-year study and systematic review. Ann Acad Med Singapore. 2016;45:303-14.

6. Yeom JS, Ryu SH, Oh S, Choi DH, Song KJ, Oh YH, et al. Evaluation of anti-malarial effects of mass chemoprophylaxis in the Republic of Korea army. J Korean Med Sci. 2005;20:707-12. https:/ / doi.org/10.3346/ jkms.2005.20.5.707 
7. Lee KS, Kim TH, Kim ES, Lim HS, Yeom JS, Jun G, et al. Chloroquine-resistant Plasmodium vivax in the Republic of Korea. Am J Trop Med Hyg. 2009;80:215-7. https:/ / doi.org/ 10.4269/ajtmh.2009.80.215

8. World Health Organization. Guidelines for the treatment of malaria. Geneva: World Health Organization; 2015.

9. CDC. Guidelines for treatment of malaria in the United States [updated 2019 April 1] [cited 2019 May 10].
https://www.cdc.gov/malaria/resources/pdf/Malaria_ Treatment_Table.pdf

Address for correspondence: Joon-Sup Yeom, Department of Internal Medicine, Yonsei University College of Medicine, 50-1, Yonsei-ro, Seodaemun-gu, Seoul, South Korea; email: joonsup.yeom@gmail.com

\title{
etymologia
}

\section{Acanthamoeba [ə,kæn.Өə'mi.bə]}

\author{
Nitika Pradhan
}

$\mathrm{F}$ rrom the (change) to describe this organism as having a spine-like structure (acanthopodia). This organism is now well-known as Acanthamoeba, an amphizoic, opportunistic, and nonopportunistic protozoan protist widely distributed in the environment.

In 1930, it was reported by Castellani in yeast (Cryptococcus pararoseus) culture, and was later (1931) classified as the genus Acanthamoeba by Volkonsky. It was later found to be the etiologic agent of Acanthamoeba granulomatous encephalitis and keratitis in humans. This organism can also cause cutaneous acanthamebiasis in debilitated and immunocompromised patients.

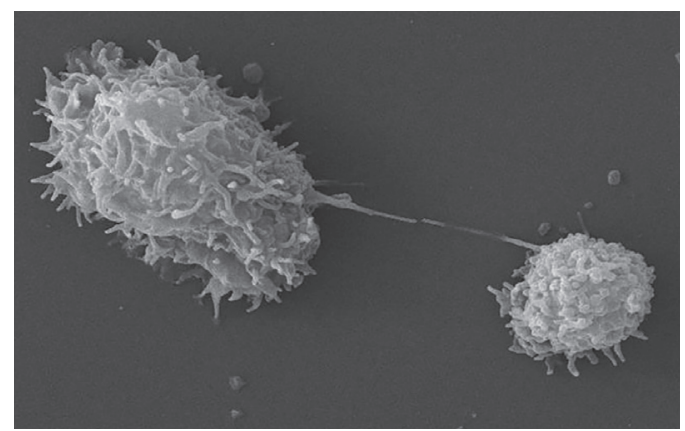

This scanning electron microscopic image shows an Acanthamoeba polyphaga protozoa about to complete the process of cell division known as mitosis, thereby becoming 2 distinct organisms. Note the numerous pseudopodia projecting from the surfaces of these organisms. These pseudopodia enable the amoebae to move about and grasp objects in their environment. Source: Centers for Disease Control and Prevention/ Catherine Armbruster, Margaret William; photograph, Janice Haney Carr, 2009.

\section{Sources}

1. Castellani A. An amoeba found in culture of yeast: preliminary note. J Trop Med Hyg. 1930;33:160.

2. De Jonckheere JF. Ecology of Acanthamoeba. Rev Infect Dis. 1991;13(Suppl 5):385-7. https:// doi. org/10.1093/clind/13.Supplement_5.S385

3. Khan NA. Acanthamoeba: biology and increasing importance in human health. FEMS Microbiol Rev. 2003;16:273-307.

\footnotetext{
Author affiliation: Kalinga Institute of Industrial Technology, Bhubaneswar, India

Address for correspondence: Nitika Pradhan, Kalinga Institute of Industrial Technology, Bhubaneswar, India; email: nitikapradhan32@gmail.com
}

DOI: https://doi.org/10.3201/eid2608.ET2608 